\title{
PENILAIAN DAN PENGENDALIAN RISIKO PADA PEKERJAAN BONGKAR MUAT PETI KEMAS OLEH TENAGA KERJA BONGKAR MUAT DENGAN CRANE
}

\author{
Senjayani $^{1}$, Tri Martiana ${ }^{2}$ \\ ${ }^{1}$ Program Studi S1 Kesehatan Masyarakat, Fakultas Kesehatan Masyarakat, Universitas Airlangga \\ ${ }^{2}$ Departemen Kesehatan dan Keselamatan Kerja, Fakultas Kesehatan Masyarakat, Universitas \\ Airlangga \\ senjayani.gumay@gmail.com
}

\begin{abstract}
Port is the distribution center of commodity with the intensive rigging activities. There are two types of rigging activities, namely manual rigging and rigging by crane. Rigging by crane is high risk job. The purpose of this study is to conduct a risk assessment of container rigging activity at Terminal South Jamrud. This research was conducted with observational approach. The object of this study is container rigging work by crane. The result of hazard identification on this activity show that there are 17 hazard potential. Risk assessment categorize seven of the hazard potentials as low risk, six of the hazard potentials as medium risk, and four of the hazard potentials as high risk. Risk control which has been applied consist of engineering control, administrative control and personal protective equipment (PPE). The hazard of rigging activities by crane control effort has been made to stage the ALARP (As Low As Possible Reasonably Practicable). Koperasi TKBM Usaha Karya and PT Pelabuhan Indoensia III (PERSERO) Cabang Tanjung Perak need to conduct proper rigging training by crane on a periodic basic for all of their rigger. Applying reward and punishment can be implemented accordingly by PT Pelabuhan Indonesia III (PERSERO) Cabang Tanjung Perak to spur obedience as well as improving productivity.
\end{abstract}

Keyword: risk assessment, rigger, crane

\begin{abstract}
ABSTRAK
Pelabuhan merupakan pusat distribusi barang yang didalamnya terdapat kegiatan bongkar muat. Ada dua macam jenis kegiatan bongkar muat yaitu kegiatan bongkar muat manual dan kegiatan bongkar muat dengan crane. Kegiatan bongkar muat dengan crane merupakan pekerjaan yang berisiko tinggi. Adapun tujuan penelitian ini yaitu melakukan risk assessment pada pekerjaan bongkar muat peti kemas. Penelitian ini dilaksanakan dengan rancangan deskriptif dengan pendekatan observasional. Objek yang diteliti yaitu pekerjaan bongkar muat peti kemas dengan crane. Hasil identifikasi bahaya menunjukkan 17 potensi bahaya yang teridentifikasi. Penilaian risiko menunjukkan 7 potensi bahaya masuk kategori low risk, 6 potensi bahaya masuk katergori medium risk dan 4 potensi bahaya masuk kategori high risk. Pengendalian risiko yang dilakukan terdiri dari pengendalian teknik, pengendalian administratif dan alat pelindung diri (APD). Bahaya pekerjaan bongkar muat dengan crane telah dilakukan upaya pengendalian hingga tahap ALARP (As Low As Possible Reasonably Practicable). Koperasi Usaha Karya dan PT Pelabuhan Indonesia III (PERSERO) Cabang Tanjung Perak perlu melakukan pelatihan terkait dengan bongkar muat peti kemas dengan crane secara periodik pada setiap tenaga kerja bongkar muat. Pemberian punishment dan reward dapat dilakukan oleh PT Pelabuhan Indonesia III (PERSERO) Cabang Tanjung Perak sebagai bentuk memacu ketaatan tenaga kerja bongkar muat sekaligus memacu meningkatkan produktivitas kerja.
\end{abstract}

Kata kunci: risk assessment, tenaga kerja bongkar muat, crane 
Senjayani, et al. Penilaian dan Pengendalian Risiko Pada Pekerjaan Bongkar Muat Peti Kemas Oleh Tenaga Kerja Bongkar Muat Dengan Crane
JPH RECODE Maret 2018; 1 (2) : 120-130 http://e-journal.unair.ac.id/JPHRECODE

\section{PENDAHULUAN}

Kegiatan bongkar muat merupakan kegiatan pemindahan barang dari dermaga ke kapal dan begitupun sebaliknya. Kegiatan bongkar muat dapat dipermudah dengan adanya crane kapal. Crane adalah peralatan angkat angkut yang difungsikan khusus untuk mengangkat naik dan menurunkan muatan (Menteri Tenaga Kerja dan Transmigrasi, 1985).

Kegiatan bongkar muat dilakukan oleh tenaga kerja bongkar muat yang dikelola oleh koperasi. Tenaga kerja bongkar muat bertugas memasang atau melepaskan peti kemas pada alat pengangkat atau hook crane. Potensi bahaya yang sering terjadi pada tenaga kerja bongkar muat maupun operator crane antara lain terjepit beban, tertimpa beban, dan terpleset saat naik tangga.

Data dari PT PELINDO I Cabang Pekanbaru menyebutkan kecelakaan kerja pada pekerjaan bongkar muat dengan crane yang terjadi di Dermaga A PT Pelabuhan Indonesia I Cabang Pekanbaru. Kecelakaan yang terjadi pada tanggal 12 November 2009 ini disebabkan karena operator crane tidak memperhatikan kapasitas beban yang dapat diangkat oleh crane sehingga beban yang diangkat melebihi kapasitas. Akibatnya boom crane yang digunakan patah yang menyebabkan 1 (satu) orang tenaga kerja bongkar muat meninggal dan 1 (satu) orang tenaga kerja bongkar muat lain harus menjalani perawatan intensif di rumah sakit.

Data kecelakaan lain dari berita harian Suara Pekerja menyebutkan kecelakaan pada bulan April 2012 hingga bulan Maret 2013 terjadi 3 (tiga) kali kecelakaan di Terminal Nilam Tanjung Perak Surabaya yang megakibatkan 3 (tiga) tenaga kerja bongkar muat meninggal dunia. Dua kecelakaan terjadi pada saat bongkar muat kayu gelondongan. Satu kecelakaan berasal dari kegiatan bongkar muat tiang pancang saat melakukan bongkar muat barang dari dermaga ke kapal. Tarwaka (2008) menyebutkan sebab utama dari kejadian kecelakaan kerja adalah unsafe action dan unsafe condition.

Data Kementerian Tenaga Kerja dan Transmigrasi menyebutkan, sepanjang tahun 2009 telah terjadi 54. 398 kasus kecelakaan kerja di Indonesia, sedangkan data yang bersumber dari Jamsostek menunjukkan total angka kecelakaan kerja periode 2010 mencapai 86.693 kasus kecelakaan kerja. Penelitian yang dilakukan oleh ILO (International Labour
Organization) 1998 membuktikan bahwa setiap rata-rata 6.000 orang manusia meninggal dunia, setara dengan satu orang setiap kurun waktu 15 detik atau 2.2 juta orang pertahun akibat sakit atau kecelakaan kerja yang berkaitan dengan pekerjaan mereka (Suardi, 2007). Data tersebut menggambarkan bahwa begitu besarnya kerugian yang didapatkan akibat adanyapotensi bahaya yang tidak dikehendaki.

Suma'mur (2009) menyebutkan bahwa pengendalian sumber-sumber bahaya harus dilakukan yaitu dengan melakukan identifikasi sumber-sumber potensi bahaya di tempat kerja. Upaya pengendalian risiko harus dilakukan salah satu upaya yang dapat dilakukan yaitu dengan cara risk assessment. Risk assessment merupakan bagian dari manajemen risiko yang mencakup dua tahapan yaitu analisis risiko dan evaluasi risiko, kedua tahapan ini akan menentukan langkah pengendalian risiko yang dapat dilakukan untuk mengurangi potensi bahaya di tempat kerja (Ramli, 2010). Salah satu contohnya pengendalian risiko yang dilakukan oleh pada engine room kapal feri selat Madura II Surabaya menjelaskan bahwa terdapat beberapa pengendalian risiko yang dilakukan diantaranya pemasangan safety device, pengendalian administratif, dan APD (Wicaksono, 2017).

Risk assessment sebagai wujud dari risk management perlu dilaksanakan untuk mengetahui besarnya nilai risiko yang dapat terjadi pada pekerjaan bongkar muat peti kemas dengan crane. Risk assessment bertujuan menurunkan risiko hingga tingkat risiko yang bisa terima oleh Manajemen sehingga menciptakan kondisi aman di tempat kerja. Adapun tujuan dari penelitian ini yaitu melakukan risk assessment pada pekerjaan bongkar muat peti kemas dengan crane oleh tenaga kerja bongkar muat di Terminal Jamrud Selatan Pelabuhan Tanjung Perak.

\section{METODE}

Penelitian ini dilaksanakan dengan rancangan deskriptif dengan metode observasional. Penelitian ini termasuk penelitian cross sectional karena pengamatan pada variabel dilakukan berdasarkan periode tertentu saja. Data dikumpulkan dengan melakukan observasi terhadap pekerjaan bongkar muat dan wawancara terhadap tenaga kerja bongkar muat dan supervisor bongkar muat.

Objek yang diteliti yaitu pekerjaan bongkar muat peti kemas dengan crane. 
Senjayani, et al. Penilaian dan Pengendalian Risiko Pada Pekerjaan Bongkar Muat Peti Kemas Oleh Tenaga Kerja Bongkar Muat Dengan Crane

Penelitian dilakukan pada bulan Oktober 2015 - Desember 2015. Data penelitian yang diukur antara lain identifikasi bahaya pekerjaan bongkar muat dengan crane, penilaian risiko pada pekerjaan bongkar muat dengan crane dan mengamati pengendalian risiko yang sudah dilakukan di Terminal Jamrud Selatan.

Teknik dan instrumen pengumpulan data adalah: (a) langkah awal melakukan pengumpulan data dengan melakukan observasi awal, kemudian membuatlembar job safety analysis (JSA) terkait pekerjaan bongkar muat peti kemas dengan crane, (b) observasi yang dilakukan secara langsung untuk mengetahui sumberbahayadengan cara melihat langsung, mendengar dan mencatat keadaan di tempat kerja mengenai potensi bahaya yang ada pada pekerjaan bongkar muat peti kemas menggunakan crane, (c) wawancaradengan tenaga kerja bongkar muat dan supervisor bongkar muat dengan tujuanuntuk menggali informasi dan keterangan terkait dengan manajemen risiko pada pekerjaan bongkar muat peti kemas dengan crane, instrumen yang digunakan berupa lembar kuisioner.

Standar yang digunakan untuk melakukan penilaian risiko yaitu menggunakan Australian Standard/New Zealand Standard tahun 2004 (Australian Standard/New Zealand Standard, 2004). Sebelumnya dilakukan identifikasi bahaya dengan menentukan potensi bahaya berikut risiko yang bisa terjadi. Hasil dari identifikasi bahaya kemudian disepakati nilai severity dan likelihood. Likelihood (kemungkinan) adalah proses menentukan suatu bahaya dari aktivitas sehingga besar kemungkinan potensi bahaya dapat diketahui. Severity (keparahan) adalah dampak yang dari suatu aktivitas kerja. Nilai likelihood dan severity kemudian dikalikanuntuk mendapatkan hasil penilaian risiko. Selanjutnya tingkat risiko dikategorikan menjadi 3 (tiga) yaitu kategori low risk (1-6), kategori medium risk (7-14) dan high risk(1525).

\section{HASIL}

\section{Identifikasi Bahaya}

Elemen pertama dari proses manajemen risiko $\mathrm{K} 3$ dimulai dengan identifikasi bahaya yang dilakukan. Penelitian ini menggunakan lembar job safety analysis (JSA) untuk meneliti potensi bahaya pada pekerjaan bongkar muat peti kemas dengan crane. Hasil identifikasi ba- haya pada pekerjaan bongkar muat dapat dilihat pada Tabel 2.

\section{Penilaian Risiko}

Penilaian risiko adalah proses analisis dan evaluasi risiko untuk menentukan besarnya risiko serta tingkat risiko. Potensi bahaya perlu diamati agar dapat mengetahui besarnya risiko yang dapat terjadi. Berdasarkan observasi dan wawancara di lapangan, hasil penilaian risiko pada pekerjaan bongkar muat peti kemas dengan crane dijelaskan pada Tabel 2 .

\section{Pengendalian Risiko}

Risiko yang telah diketahui besarnya potensi bahaya harus dikelola dengan tepat dan efektif sesuai kemampuan perusahaan. Pengendalian risiko merupakan langkah penting yang menentukan keseluruhan manajemen risiko. Hirarki pengendalian risiko diterapkan untuk mengurangi kemungkinn dan keparahan dari suatu aktivitas. Ada enam tingkatan pengendalian risiko yaitu eliminasi, substitusi, teknik, isolasi, administratif dan alat pelindung diri (APD). Pengendalian risiko yang sudah dilakukan di Terminal Jamrud Selatan terdiri dari teknik, administratif dan alat pelindung diri (APD). 
Tabel 2. Hasil Identifikasi Bahaya dan Penilaian Risiko Pada Pekerjaan Bongkar Muat Peti Kemas

\begin{tabular}{|c|c|c|c|c|c|c|}
\hline \multirow{2}{*}{$\begin{array}{l}\text { Aktivitas } \\
\text { Pekerjaan }\end{array}$} & \multirow{2}{*}{ Uraian } & \multirow{2}{*}{ Potensi Bahaya } & \multirow{2}{*}{ Risiko } & \multicolumn{3}{|c|}{$\begin{array}{l}\text { Peringkat } \\
\text { Risiko }\end{array}$} \\
\hline & & & & $\begin{array}{l}\mathbf{L} \\
\mathbf{L}\end{array}$ & & $\begin{array}{l}\mathbf{R} \\
\mathbf{S}\end{array}$ \\
\hline \multirow{4}{*}{$\begin{array}{l}\text { Memasang } \\
\text { tangga } \\
\text { atas truk }\end{array}$} & \multirow[t]{2}{*}{ Mengangkat tangga } & $\begin{array}{l}\text { Terpapar asap ken- } \\
\text { daraan bergerak }\end{array}$ & $\begin{array}{l}\text { Gangguan } \\
\text { pernafasan }\end{array}$ & 2 & 1 & 2 \\
\hline & & $\begin{array}{l}\text { Beban tangga yang } \\
\text { berat }\end{array}$ & Low back pain & 4 & & 4 \\
\hline & \multirow[t]{2}{*}{$\begin{array}{l}\text { Memposisikan } \\
\text { pada ujung truk }\end{array}$} & Tertimpa tangga & $\begin{array}{l}\text { Luka gores, me- } \\
\text { mar }\end{array}$ & 2 & 3 & 6 \\
\hline & & $\begin{array}{l}\text { Posisi badan mem- } \\
\text { bungkuk }\end{array}$ & Low back pain & 4 & 1 & 4 \\
\hline \multirow[t]{2}{*}{$\begin{array}{l}\text { Naik/turun } \\
\text { truk }\end{array}$} & \multirow[t]{2}{*}{$\begin{array}{l}\text { Berjalan } \\
\text { menuruni truk }\end{array}$} & Tersandung & $\begin{array}{l}\text { Memar, luka } \\
\text { serius, patah tu- } \\
\text { lang }\end{array}$ & 3 & 4 & 12 \\
\hline & & Tangga patah & $\begin{array}{l}\text { Memar, luka } \\
\text { serius, patah tu- } \\
\text { lang }\end{array}$ & 3 & 4 & 12 \\
\hline \multirow[t]{4}{*}{$\begin{array}{l}\text { Pengangkata } \\
\mathrm{n} \text { peti kemas }\end{array}$} & $\begin{array}{l}\text { Memasang hook crane } \\
\text { pada peti kemas }\end{array}$ & $\begin{array}{l}\text { Tangan terjepit hook } \\
\text { crane }\end{array}$ & $\begin{array}{l}\text { Luka gores, me- } \\
\text { mar }\end{array}$ & 3 & 2 & 6 \\
\hline & \multirow[t]{3}{*}{$\begin{array}{l}\text { Pengangkatan peti kemas } \\
\text { dengan crane }\end{array}$} & $\begin{array}{l}\text { Peti kemas berayun } \\
\text { cepat }\end{array}$ & $\begin{array}{l}\text { Luka serius, } \\
\text { patah tulang, } \\
\text { cacat, kematian }\end{array}$ & 2 & & 10 \\
\hline & & Tertimpa peti kemas & $\begin{array}{l}\text { Luka serius, } \\
\text { patah tulang, } \\
\text { cacat, kematian }\end{array}$ & 3 & 5 & 15 \\
\hline & & Tali sling putus & $\begin{array}{l}\text { Luka serius, } \\
\text { patah tulang, } \\
\text { cacat, kematian }\end{array}$ & 3 & & 15 \\
\hline \multirow[t]{3}{*}{$\begin{array}{l}\text { Pemberian } \\
\text { sinyal tangan }\end{array}$} & \multirow[t]{3}{*}{$\begin{array}{l}\text { Berdiri di atas kapal } \\
\text { memberikan sinyal }\end{array}$} & $\begin{array}{l}\text { Paparan sinar ma- } \\
\text { tahari }\end{array}$ & $\begin{array}{l}\text { Heat exhaustion } \\
\text { (kelelahan panas) }\end{array}$ & 3 & & 6 \\
\hline & & Tertabrak peti kemas & $\begin{array}{l}\text { Luka serius, } \\
\text { patah tulang, } \\
\text { cacat, kematian }\end{array}$ & 2 & 5 & 10 \\
\hline & & Jatuh ke laut & $\begin{array}{l}\text { Tenggelam, ke- } \\
\text { matian }\end{array}$ & 3 & & 12 \\
\hline \multirow[t]{4}{*}{$\begin{array}{l}\text { Penurunan } \\
\text { peti kemas }\end{array}$} & \multirow[t]{3}{*}{$\begin{array}{l}\text { Penurunan peti kemas ke } \\
\text { kapal }\end{array}$} & $\begin{array}{l}\text { Terkena siku peti } \\
\text { kemas }\end{array}$ & $\begin{array}{l}\text { Luka gores, me- } \\
\text { mar, cidera pada } \\
\text { kepala }\end{array}$ & 3 & 4 & 12 \\
\hline & & Tali sling putus & $\begin{array}{l}\text { Luka serius, } \\
\text { patah tulang, } \\
\text { cacat, kematian }\end{array}$ & 3 & 5 & 15 \\
\hline & & Tertimpa peti kemas & $\begin{array}{l}\text { Luka serius, } \\
\text { patah tulang, } \\
\text { cacat, kematian }\end{array}$ & 3 & 5 & 15 \\
\hline & $\begin{array}{l}\text { Melepas hook crane pada } \\
\text { peti kemas }\end{array}$ & $\begin{array}{l}\text { Tangan terjepit hook } \\
\text { crane }\end{array}$ & $\begin{array}{l}\text { Luka gores, me- } \\
\text { mar }\end{array}$ & 3 & 2 & 6 \\
\hline
\end{tabular}


Senjayani, et al. Penilaian dan Pengendalian Risiko Pada Pekerjaan Bongkar Muat Peti Kemas Oleh Tenaga Kerja Bongkar Muat Dengan Crane
JPH RECODE Maret 2018; 1 (2) : 120-130 http://e-journal.unair.ac.id/JPHRECODE

\section{PEMBAHASAN}

\section{Identifikasi Bahaya}

Persyaratan yang ditentukan OHSAS 18001, setiap perusahaan harus menetapkan prosedur mengenai identifikasi bahaya (OHSAS 18001:2007, 2007). Siswanto (2012) menyebutkan identifikasi bahaya adalah proses mengenal bahaya dan menetapkan karakteristik bahaya tersebut

Kegiatan mengidentifikasi bahaya merupakan tahap pertama dalam manajemen risiko untuk mengetahui masalah keselamatan dan kesehatan kerja yang ada dalam proses kerja di perusahaan. Identifikasi bahaya sangat penting untuk menentukan bentuk program keselamatan dan kesehatan kerja dan implementasi pengendalian yang harus dilakukan perusahaan. Hasil identifikasi menjadi masukan utama dalam menyusun rencana kerja untuk mengendalikan dan mencegah kejadian yang tidak diinginkan dari keberadaan bahaya tersebut.

Metode yang digunakan dalam mengidentifikasi bahaya adalah metode proaktif sehingga potensi bahaya yang terdapat pada pekerjaan diidentifikasi sejak awal sebelum terjadinya kecelakaan. Dari dan Indriati (2013) menyebutkan, hasil identifikasi bahaya dengan menggunakan metode proaktif akan bernilai positif karena sifatnya yang preventif. Ramli (2010) menyebutkan, metode proaktif akan membentuk peningkatan berkelanjutan, menghindarkan dari pemborosan dan meningkatkan awareness. Hal ini dirasa efektif untuk menekan kerugian yang berlebih sebelum terjadinya kecelakaan kerja yang tidak diharapkan. Lembar Job Safety Analysis (JSA) digunakan untuk memberikan kemudahan saat melakukan identifikasi bahaya pada setiap tahapan kerja proses bongkar muat. Identifikasi bahaya pada proses bongkar muat dilakukan dengan memperhatikan proses pekerjaan dari tahap persiapan hingga tahap akhir.

Identifikasi bahaya proses bongkar muat dengan crane meliputi aktivitas tenaga kerja bongkar muat memasang tangga ke atas truk, naik/ turun truk, pengangkatan peti kemas, pemberian sinyal tangan, dan penurunan peti kemas. Aktivitas yang pertama kali dilakukan yaitu memasang tangga ke atas truk. Truk yang tiba di Dermaga akan dipasang tangga di atas truk sebagai akses naik/ turun truk. Tenaga kerja bongkar muat yang mengangkat tangga ada 2 potensi bahaya yang dapat terjadi yaitu beban tangga yang berat, dan terpapar asap kendaraan/ truk. Beban tangga yang berat berisiko low back pain. Potensi bahaya terpapar asap kendaraan yaitu gangguan pernafasan. Riski (2013) menyebutkan bahwa asap kendaraan bergerak beserta debu yang masuk dalam saluran pernafasan dan mengendap dalam paru dalam jangka waktu lama akan menyebabkan gangguan kesehatan seperti gangguan pernafasan, ISPA, bronchitis, TBC, asma, dan ganguan pernafasan lainnya.

Potensi bahaya tertimpa tangga yaitu luka gores dan memar, sedangkan risiko dari potensi bahaya badan membungkuk yaitu low back pain. Aktivitas selanjutnya yaitu tenaga kerja bongkar muat naik/ turun truk, potensi bahaya yang terjadi adalah tersandung dan tangga yang sewaktu-waktu bisa patah. Risiko yang terjadi akibat tersandung yaitu tenaga kerja bongkar muat dapat memar, luka serius, dan patah tulang. Tangga yang patah dapat berisiko memar, luka serius, dan patah tulang. Tenaga kerja bongkar muat dituntut untuk selalu menggunakan alat pelindung diri (APD) saat bekerja, hal ini sesuai dengan Undang-Undang Nomor 1 Tahun 1970 pasal 13 mengenai seorang pekerja wajib untuk menggunakan alat pelindung diri (APD) sebelum melakukan pekerjaannya (Departemen Hukum dan Perundang-Undangan, 1970).

Ada banyak faktor yang menyebabkan tenaga kerja bongkar muat tidak menggunakan alat pelindung diri (APD). Ghaisani dan Erwin (2014) menyebutkan bahwa penggunaan alat pelindung diri (APD) membatasi ruang gerak pekerja ketika bekerja. Hasil observasi menyimpulkan bahwa pekerja belum mengetahui dampak atau efek buruk dari tidak menggunakan alat pelindung diri (APD).

Aktivitas selanjutnya yaitu tenaga kerja bongkar muat memasang hook crane. Potensi bahaya yang terjadi yaitu tangan terjepit hook crane. Risiko yang bisa terjadi dari potensi tersebut yaitu memar dan luka gores.

Pengangkatan peti kemas dengan crane potensi bahaya yang terjadi yaitu peti kemas berayun cepat, tali sling putus dan tertimpa peti kemas. Tiga potensi bahaya ini mempunyai risiko yang sama yaitu luka serius, patah tulang, cacat, kematian. Tenaga kerja bongkar muat harus fokus saat melakukan pekerjaan, khususnya pada saat proses pengangkatan peti kemas. Kecelakaan dapat saja terjadi sewaktu-waktu. 
Senjayani, et al. Penilaian dan Pengendalian Risiko Pada Pekerjaan Bongkar Muat Peti Kemas Oleh Tenaga Kerja Bongkar Muat Dengan Crane

Aktivitas selanjutnya yaitu pemberian sinyal tangan, satu orang tenaga kerja bongkar mut yang berada di atas kapal memberikan sinyal tangan pada operator crane yang menandakan bahwa peti kemas sudah siap untuk diangkat. Potensi bahaya yang terjadi pada tenaga kerja bongkar muat yang memberikan sinyal tangan yaitu ada tiga tertabrak peti kemas, terpapar sinar matahari dan terjatuh ke laut. Risiko yang terjadi akibat tertabrak peti kemas sangat serius yaitu luka serius, patah tulang, cacat dan kematian. Kewaspadaan saat bekerja harus diperhatikan oleh tenaga kerja bongkar muat, agar tidak terjadi hal yang tidak diiingkan.

Risiko dari potensi bahaya terpapar sinar matahari yaitu heat exhaustionm (kelelahan panas). Kelelahan panas merupakan kondisi gejala yang mencakup berkeringat berat dan denyut nadi cepat, akibat dari tubuh yang terlalu panas. Penyebab kelelahan panas yaitu dari paparan suhu tinggi dan aktivitas fisik yang berat. Potensi bahaya terjatuh ke laut dapat menyebabkan risiko tenggelam hingga kematian. Pihak Terminal Jamrud Selatan harus menyediakan life jacket untuk menghindari kemungkinan tenggelam pada tenaga kerja bongkar muat.

Aktivitas terakhir yaitu penurunan peti kemas di palka kapal. Aktivitas penurunan peti kemas dilakukan olej empat orang tenaga kerja bongkar muat sudah bersiap menunggu peti kemas. Dua orang tenaga kerja bongkar muat memastikan bahwa posisi mendaratnya peti kemas sudah benar dan dua orang lagi bertugas melepas hook crane. Potensi bahaya yang terjadi saat penurunan peti kemas ada tiga yaitu peti kemas berayun cepat, tali sling putus dan tertimpa peti kemas. Tiga potensi bahaya ini mempunyai risiko yang sama yaitu luka serius, patah tulang, cacat, hingga kematian. Standar operasional bongkar muat harus dievaluasi dalam jangka waktu paling sedikit satu kali dalam periode enam bulan.

Identifikasi bahaya pada pekerjaan bongkar muat peti kemas menunjukkan ada 5 (lima) aktivitas pekerjaan bongkar muat yang diteliti. Lima aktivitas pekerjaan bongkar muat tersebut membentuk delapan uraian yang masing-masing menjelaskan prosedur dari proses pekerjaan bongkar muat. Hasil akhir identifikasi bahaya menunjukkan terdapat 17 potensi bahaya yang teridentifikasi.
JPH RECODE Maret 2018; 1 (2) : 120-130

http://e-journal.unair.ac.id/JPHRECODE

\section{Penilaian Risiko}

Setelah identifikasi bahaya selesai, dilakukan penilaian tingkat risiko dengan menggunakan teknik semi kuantitatif. Penilaian risiko adalah proses menilai besar risiko berdasarkan potensi bahaya berikut risiko yang telah teridentifikasi pada proses bongkar muat. Penentuan nilai likelihood dan severity dari setiap potensi bahaya yang telah teridentifikasi dan besarnya risiko yang ditimbulkan disepakati dengan pihak perusahaan terkait. Penilaian risiko yang didapatkan dari hasil perkalian antara tingkat keparahan (severity) dilambangkan dengan huruf (S), tingkat kemungkinan (likelihood) yang dilambangkan dengan huruf (L).

Nilai atau tingkat keparahan (severity) merupakan nilai berdasarkan akibat yang ditimbulkan dari setiap potensi bahaya yang dapat dilihat dari hasil observasi. Nilai atau tingkat kemungkinan (severity) merupakan kemungkinan terjadinya suatu potensi bahaya paparan. Hasil perkalian likelihood dan severity kemudian dievaluasi menggunakan lembar job safety analysis (JSA) sehingga dapat menyimpulkan potensi bahaya tersebut termasuk dalam kategori risiko rendah, sedang atau tinggi.

Penilaian risiko yang pertama dilakukan pada aktivitas memasang tangga. Uraian kerja melakukan pemasangan tangga, dimulai dengan mengangkat tangga. Potensi bahaya terpapar asap kendaraan menyebabkan risiko gangguan pernafasan diberikan nilai 2 untuk likelihood dengan nilai 1 untuk severity. Nilai tersebut didapatkan atas dasar karena risiko yang didapatkan terkategori low risk dengan yaitu dengan nilai 2 .

Beban tangga yang berat berisiko menimbulkan low back pain diberikan nilai 4 untuk likelihood, yang artinya kejadian tersebut sering dirasakan oleh tenaga bongkar muat. Hasil wawancara dengan tenaga kerja bongkar muat menyebutkan nyeri punggung (low back pain) sering dikeluhkan oleh tenaga kerja bongkar muat, hal ini diprediksikan karena beban tangga yang berat. Nilai severity yang diberikan 1, yang artinya dapat diabaikan dan dapat diatasi dengan cara pergantian shift kerja saat merasa lelah.

Tenaga kerja bongkar muat yang memposisikan tangga pada truk berpotensi bahaya tertimpa tangga dengan risiko luka gores dan memar diberikan nilai 2 untuk likelihood karena kemungkinan terjadinya kecil. Nilai severity 
Senjayani, et al. Penilaian dan Pengendalian Risiko Pada Pekerjaan Bongkar Muat Peti Kemas Oleh Tenaga Kerja Bongkar Muat Dengan Crane

yang didapatkan 3, nilai tersebut atas dasar kecelakaan terjadi apabila ada faktor tambahan. Hasil akhirnya yaitu masuk kategori low risk.

Posisi badan membungkuk yang berisiko low back pain diberikan nilai 4 untuk likelihood, yang artinya kejadian tersebut sering dirasakan oleh tenaga bongkar muat. Nilai severity yang diberikan 1, yang artinya dapat diabaikan dan dapat diatasi dengan cara pergantian shift kerja saat merasa lelah. Hasil akhir perhitungan penilaian yaitu 4 yang artinya masuk kategori low risk.

Aktivitas naik/ turun truk dimulai dengan berjalan menaiki/ menuruni truk, potensi bahayanya ada dua yaitu tersandung dan tangga patah. Potensi bahaya tersandung sangat sering terjadi akibat tenaga kerja bongkar muat tidak fokus atau kelelahan saat bekerja, sehingga nilai likelihood yang diberikan adalah 3 . Kesakitan yang diderita cukup signifikan, yang menyebabkan memar, luka serius hingga patah tulang sehingga nilai severity yang didapatkan adalah 12. Hasil akhir dengan nilai 12 masuk dalam kategori medium risk.

Penilaian risiko pada potensi bahaya tangga patah yang menyebabkan risiko memar, luka serius dan patah tulang diberikan penilaian 3 untuk likelihood. Nilai 3 didapatkan karena faktor tambahan yang dapat melatarbelakangi terjadinya kecelakaan terjadinya tangga patah. Nilai severity yang didapatkan adalah 4 , yang artinya risiko memar, luka serius hingga patah tulang terkategori high. Penilaian risiko pada potensi bahaya tangga patah mendapatkan hasil 12 yang terkategori medium risk.

Tenaga kerja bongkar muat yang sudah berada di atas truk memasang hook crane. Tenaga kerja bongkar muat yang memasang hook crane potensi bahaya yang dapat terjadi yaitu memar dan luka gores. Kejadian memar dan luka gores dapat terjadi apabila tenaga kerja bongkar muat tidak menggunakan alat pelindung diri (APD) berupa sarung tangan. Pihak Koperasi Usaha Karya sendiri sudah memberikan masing-masing tenaga kerja bongkar muat sarung tangan. Nilai likelihood yang diberikan adalah 3 yang artinya kesalahan dapat terjadi karena faktor tambahan. Risiko yang didapatkan dari potensi bahaya tergolong rendah sehingga diberikan nilai 2 untuk severity.

Aktivitas saat pengangkatan peti kemas, teridentifikasi tiga potensi bahaya yaitu mulai dari peti kemas yang berayun cepat. Potensi bahaya peti kemas berayun cepat diberikan nilai 3 untuk likelihood yang artinya faktor tamba-
JPH RECODE Maret 2018; 1 (2) : 120-130 http://e-journal.unair.ac.id/JPHRECODE

han yang bisa melatar belakangi terjadinya kecelakaan ini, selanjutnya nilai severity yang didapatkan adalah 5 karena kecelakaan ini dapat menyebabkan kematian. Penilaian risiko yang didapatkan terkategori high risk yang artinya pihak Terminal Jamrud Selatan harus melakukan pengendalian risiko untuk mengendalikan potensi bahaya ini.

Tenaga kerja bongkar muat berpotensi tertimpa peti kemas saat operator crane lalai dalam mengendari crane. Potensi bahaya tertimpa peti kemas sangat jarang terjadi, namun apabila ada faktor tambahan yang mempengaruhinya maka kecelakaan tertimpa peti kemas dapat terjadi, untuk itu nilai likelihood diberikan nilai 3 . Nilai severity yang didapatkan yaitu 5 , karena risiko yang terjadi dapat menyebabkan luka serius, patang tulang hingga kematian. Hasil akhir menunjukkan tertimpa peti kemas masuk area merah atau high risk. Ramli (2010) menyebutkan, dalam konsep ALARP risiko tinggi atau yang berada pada area merah adalah risiko tidak dapat ditolerir lagi, sehingga dilakukan langkah pengendalian risiko.

Tali sling dapat sewaktu-waktu putus saat tenaga kerja bongkar muat bekerja, pengecekan secara rutin secara berkala harus dilakukan untuk memelihara tali sling. Potensi bahaya ini sangat jarang terjadi, namun dapat terjadi apabila terjadi kelalaian dengan tidak memeriksa tali sling sebelum bekerja untuk itu nilai likelihood yang diberikan 3. Nilai severity yang diberikan 5 yang artinya risiko yang didapatkan menimbulkan kesakitan yang serius hingga kematian. Kejadian tali sling putus masuk kategori high risk.

Tali sling harus diperiksa pada waktu pemasangan pertama dan setiap hari oleh operator crane dan supervisor bongkar muat, serta sekurang-kurangnya satu kali dalam seminggu oleh teknisi maintenance crane. Jadwal pelumasan dilakukan setiap satu bulan sekali, sedangkan jadwal pergantian tali sling yang baru dilakukan setiap delapan bulan sekali. Hal ini sesuai dengan Peraturan Menteri Tenaga Kerja No 5 Tahun 1985 tentang Pesawat Angkat dan Angkut.

Aktivitas pemberian sinyal tangan dilakukan oleh salah satu tenaga kerja bongkar muat yang berdiri di atas kapal. Potensi bahaya dari aktivitas ini cukup serius, tenaga kerja bongkar muat harus memakai alat pelindung diri (APD) lengkap untuk menghindari terjadinya kecelakaan yang tidak diinginkan. Helm 
Senjayani, et al. Penilaian dan Pengendalian Risiko Pada Pekerjaan Bongkar Muat Peti Kemas Oleh Tenaga Kerja Bongkar Muat Dengan Crane

safety berfungsi untuk melindungi kepala tenaga kerja bongkar muat dari benturan, dapat juga menghindari dari terik matahari. Paparan matahari dapat menyebabkan heat exhaustion yang artinya terjadi kelalahan panas akibat panas berlebih. Penilaian risiko pada paparan panas diberikan nilai 3 untuk likelihood. Sedangkan nilai severity yang didapatkan yaitu 2 karena risiko yang didapatkan terkategori low risk.

Pemberian sinyal tangan berpotensi tertabrak peti kemas. Risiko tertabrak peti kemas dapat menyebabkan luka serius, patah tulang hingga kematian. Operator crane dan pemberi sinyal tangan harus sama-sama berhati-hati dalam bekerja agar tidak terjadi kecelakaan ini. Pemberian nilai likelihood diberikan nilai 3, karena kecelakaan ini dapat terjadi disebabkan faktor tambahan seperti yang dijelaskan sebelumnya. Risiko yang didapatkan menyebabkan kesakitan luka serius hingga kematian, untuk itu nilai severity yang diberikan sebesar 5. Hasil akhir perhitungan penilaian yaitu 15 yang artinya masuk kategori high risk. Ramli (2010) dalam konsep ALARP menyebutkan medium risk dan high risk perlu dilakukan pengendalian hingga nilai risiko menjadi low risk.

Potensi bahaya terjatuh ke laut dapat terjadi pada pemberi sinyal tangan. Hal ini dapat disebabkan tenaga kerja bongkar muat yang tidak memerhatikan pijakannya saat di atas kapal, tersandung atau dapat juga disebabkan karena tertabrak peti kemas. Nilai likelihood yang diberikan yaitu 3, karena faktor unsafe action yang melatabelakangi terjadinya kecelakaan ini. Nilai severity yang didapatkan senilai 4 yang artinya kecelakaan ini dapat menyebabkan tenggelam hingga kematian tunggal.

Septiana dan Mulyono (2014) menyebutkan unsafe action pekerja perlu diperhatikan lebih serius mengingat bahwa unsafe action berpotensi menimbulkan kecelakaan yang menimbulkan kerugian, baik secara non materi atau materi. Unsafe action dapat terjadi karena komitmen maupun safe behavior pelaksanaan safety kerja yang belum secara menyeluruh merata pada setiap tenaga kerja bongkar muat. Pelatihan menjadi salah satu bentuk pengendalian risiko yang bisa memberikan pengetahuan bagi setiap tenaga kerja bongkar muat tentang bahayanya unsafe action.

Pemberi sinyal tangan harus memakai life jacket saat bekerja di atas kapal untuk memandu proses pengangkatan dan penurunan peti
JPH RECODE Maret 2018; 1 (2) : 120-130

http://e-journal.unair.ac.id/JPHRECODE

kemas. Jika sewaktu-waktu terjadi kecelakaan terjatuh ke laut life jacket dapat membuat tenaga kerja bongkar muat mengapung di laut sehingga risiko tenggelam dapat diatasi. Bantuan dilakukan dengan adanya regu penolong untuk menyambut tenaga kerja bongkar muat yang tenggelam ke daratan Dermaga.

Operator crane saat menurunkan peti kemas harus hati-hati agar peti kemas mendarat di palka kapal dengan sempurna. Pada saat proses penurunan peti kemas, teridentifikasi 3 potensi bahaya. Potensi bahaya yang teridentifikasi yaitu terkena siku peti kemas, tali sling putus dan tertimpa peti kemas. Potensi bahaya terkena siku peti kemas menyebabkan cidera di kepala, luka serius, memar hingga luka serius sehingga nilai severity yang diberikan adalah 4. Nilai likelihood yang diberikan adalah 3 karena kecelakaan ini bisa terjadi akibat tenaga kerja bongkar muat yang tidak fokus atau kosentrasi dalam melihat kondisi lingkungan sekitar.

Jumlah supervisor bongkar muat yang terbatas menjadi salah satu penyebab kurangnya pengawasan dalam kegiatan bongkar muat. PT Pelabuhan Indonesia III (PERSERO) Cabang Tanjung Perak sudah sepatutnya menambah jumlah supervisor bongkar muat. Penambahan personil supervisor bongkar muat diharapkan dapat menurunkan tingkat kecelakaan yang terjadi di Terminal Jamrud Selatan.

Potensi bahaya tali sling putus dapat sewaktu-waktu terjadi, pengecekan secara rutin harus dilakukan untuk memelihara tali sling. Nilai 5 untuk severity yang artinya risiko yang didapatkan menimbulkan kesakitan yang serius yang menyebabkan luka serius, patah tulang hingga kematian. Faktor pemeriksaan tali sling yang tidak rutin dapat menyebabkan terjadinya kecelakaan kerja yang tidak diinginkan, untuk itu nilai likelihood yang diberikan 3. Kejadian tali sling putus masuk kategori high risk, pengendalian risiko lebih lanjut harus dilakukan untuk mengendalikan potensi bahaya ini.

Kejadian tertimpa peti kemas pada tenaga kerja bongkar muat sangat jarang terjadi, namun kelalaian memicu terjadinya kecelakaan ini. Faktor tambahan dapat menjadi penyebab kecelakaan ini, untuk itu nilai likelihood diberikan nilai 3. Nilai severity yang didapatkan yaitu 5, karena risiko yang terjadi dapat menyebabkan luka serius, patah tulang hingga kematian.

Peti kemas yang sudah mendarat dengan sempurna, kemudian dilepas hook crane yang dilakukan oleh dua tenaga kerja bongkar muat. 
Senjayani, et al. Penilaian dan Pengendalian Risiko Pada Pekerjaan Bongkar Muat Peti Kemas Oleh Tenaga Kerja Bongkar Muat Dengan Crane

Tenaga kerja bongkar muat memakai sarung tangan saat melepas hook crane, namun masih banyak tenaga kerja bongkar muat yang tidak menggunakan sarung tangan sehingga menyebabkan tangan terjepit pada hook crane. Risiko yang terjadi akibat tangan terjepit yaitu luka gores dan memar sehingga nilai severity yang diberikan yaitu 2. Nilai likelihood yang diberikan adalah 3, karena kejadian ini dipengaruhi oleh unsafe action dari tenaga kerja bongkar muat itu sendiri.

Hasil dari penilaian risiko dari 17 potensi bahaya menunjukkan 7 risiko masuk kategori low risk, 6 risiko masuk kategori medium risk, dan 4 risiko masuk kategorihigh risk. Hasil menunjukkan bahwa risiko dengan kategori low risk dan medium risk mempunyai selisih angka yang tidak jauh. Hasil penilaian risiko dapat menjadi gambaran bagi Terminal Jamrud Selatan dalam melakukan pengendalian risiko ke depannya.

\section{Pengendalian Risiko}

Pengendalian risiko dilakukan agar tidak menimbulkan kecelakaan kerja dan kerugian bagi perusahaan. Pengendalian risiko merupakan suatu upaya dalam mengendalikan risiko agar bisa mencegah atau setidaknya meminimalisir kerugian akibat kecelakaan kerja. Tyastanti dan Y. Denny (2014) menyebutkan, semua risiko yang yang telah diidentifikasi dan dinilai harus dilakukan pengendalian risiko, terutama jika risiko tersebut mempunyai dampak besar atau dampak signifikan yang tidak dapat diterima. Suatu risiko yang tidak dapat diterima, harus dilakukan pengendalian risiko agar tidak menimbulkan kerugian atau kecelakaan.

Pengendalian risiko merupakan langkah penting yang menentukan keseluruhan manajemen risiko. Pengendalian risiko harus dilakukan untuk mengurangi risiko sampai batas yang dapat diterima berdasarkan ketentuan peraturan dan standar yang berlaku. Bangun dan Erwin (2014) menyebutkan, prioritas pengendalian risiko sangat penting dilakukan karena terkait dengan anggaran yang harus dikeluarkan untuk setiap pengendalian. Hirarki pengendalian risiko yaitu eliminasi, substitusi, rekayasa teknik, administratif dan alat pelindung diri (APD) merupakan pengendalian risiko untuk mengurangi kemungkinan dan keparahan risiko.

Hasil observasi dan pengamatan di lapangan, Terminal Jamrud Selatan sudah melakukan tiga (3) tingkatan hirarki pengen-
JPH RECODE Maret 2018; 1 (2) : 120-130 http://e-journal.unair.ac.id/JPHRECODE dalian risiko. Pengendalian risiko yang dilakukan yaitu pengendalian teknik, pengendalian administratif dan alat pelindung diri (APD). Pengendalian teknik yang sudah dilakukan yaitu menggunakan wind speed. Pengendalian administratif yang dilakukan yaitu pelatihan bongkar muat (rigging), sertifikasi lisensi K3 untuk operator crane, pemeriksaan kondisi dan fungsi crane sebelum digunakan, pergantian shift kerja, safety sign, safety alert dan standar operasional prosedur (SOP). Pengendalian alat pelindung diri (APD) berupa pemakaian sepatu safety, helm safety, rompi keselamatan, masker dan sarung tangan.

Pengendalian teknik merupakansebuah rekayasa yang dilakukan Terminal Jamrud Selatan dalam upaya melakukan pengendalian risiko. Pengendalian teknik yang dilakukan Terminal Jamrud Selatan yaitu dengan memasang wind speed di area dermaga. Wind speed merupakan pendeteksi kecepatan angin. Wind speed memberikan manfaat dengan cara pencegahan risiko yang disebabkan dari potensi bahaya cuaca yang kurang baik berupa angin. Kecepatan angin mencapai $14 \mathrm{~m} / \mathrm{s}$, maka alarm yang berada di atas gedung office container akan berbunyi yang menandakan pekerrjaan di Terminal Jamrud Selatan harus segera dihentikan.

Ada tujuh pengendalian administratif yang sudah dilakukan Terminal Jamrud Selatan yaitu pelatihan bongkar muat (rigging), sertifikasi lisensi K3 untuk operator crane, pemeriksaan kondisi dan fungsi crane sebelum digunakan, pergantian shift kerja, safety sign, safety alert dan standar operasional prosedur (SOP). Pelatihan bongkar muat (rigging) dilakukan pada pekerjaan bongkar muat sebagai bahan peningkatan pengetahuan dan keterampilan dalam melakukan pekerjaan bongkar muat. Tenaga kerja bongkar muat juga diberikan pengetahuan terkait bekerja sesuai konsep safety di lingkungan dermaga. Rais et al (2009) menyebutkan pengetahuan tenaga kerja bongkar muat tentang $\mathrm{K} 3$ berpengaruh terhadap praktek kerja tenaga kerja bongkar muat. Pengetahuan merupakan domain terbentuknya praktek (overt behaviour), perilaku yang didasari oleh pengetahuan akan lebih langgeng (Green dan K. M. W, 2000).

Sertifikasi lisensi K3 bagi operator crane dilakukan untuk meminimalisir bahaya kecelakaan pada saat bongkar muat peti kemas. Operator crane dituntut untuk dapat menguasai crane saat mengemudi. Hal ini sesuai dengan 
Senjayani, et al. Penilaian dan Pengendalian Risiko Pada Pekerjaan Bongkar Muat Peti Kemas Oleh Tenaga Kerja Bongkar Muat Dengan Crane

Peraturan Menteri Tenaga Kerja No 9 Tahun 2010 tentang Operator dan Petugas Pesawat Angkat dan Angkut, bahwa lisensi K3 merupakan sertifikat wajib yang harus didapat oleh operator crane melalui serangkaian pelatihan mengemudi crane (Menteri Tenaga Kerja dan Transmigrasi, 2010).

Pemeriksaan kondisi dan fungsi crane dilakukan setiap hari oleh teknisi maintenance crane. Hal ini sesuai dengan Peraturan Menteri Tenaga Kerja No 5 Tahun 1985 tentang Pesawat Angkat dan Angkut, pengecekkan crane dilakukan dengan memeriksa fungsi masingmasing alat bongkar muat termasuk alat bantunya (Menteri Tenaga Kerja dan Transmigrasi, 1985). Hal ini sebagai antisipasi terjadinya kecelakaan kerja yang disebabkan dari kegagalan alat dalam mengoperasikan sesuai fungsi yang semestinya. Pemeriksaan kondisi dan fungsi crane secara rutin juga bisa memperpanjang umur crane.

Pergantian shift kerja sangat mempengaruhi produktivitas dari kegiatan bongkar muat. Bekerja secara melebihi waktu jam kerja menyebabkkan tenaga kerja bongkar muat kelelahan. Pelaksanaan shift kerja sudah dilaksanakan di Terminal Jamrud Selatan sebagai cara mengendalikan faktor kelelahan pada setiap tenaga kerja bongkar muat.

Pengendalian administratif lain yang sudah dilakukan Terminal Jamrud Selatan yaitu safety sign. Safety sign dipasang pada area pintu masuk Terminal Jamrud Selatan berupa poster atau safety bord. Safety sign berfungsi mengingatkan atau himbauan kepada seluruh tenaga kerja bongkar muat untuk menggunakan persyaratan wajib memasuki area kerja.

Selanjutnya safety alert, safety alertditempel di safety bord pada lokasi yang sering dilewati dan menjadi titik kumpul tenaga kerja bongkar muat. Safety alert merupakan uraian kejadian unsafe action (tindakan tidak aman) maupun unsafe condition (kondisi tidak aman) yang dapat menimbulkan kecelakaan kerja. Safety alert juga diberikan prosedur kerja yang benar serta langkah antisipasi agar kejadian tidak terulang lagi.

Pengendalian administratif lainnya yang dilakukan oleh Terminal Jamrud yaitu adanya standar operasional prosedur (SOP). Setiap masing-masing jenis pekerjaan telah mempunyai SOP (Standar operasional Prosedur). SOP ditempel pada tiap sudut area kerja untuk mengingatkan tenaga kerja bongkar muat saat memulai bekerja. SOP diharapkan dapat ditaati oleh
JPH RECODE Maret 2018; 1 (2) : 120-130 http://e-journal.unair.ac.id/JPHRECODE

setiap tenaga kerja bongkar muat sehingga potensi terjadi kecelakaan dapat dihindari.

Pemakaian alat pelindung diri (APD) dilakukan untuk mengurangi keparahan jika terjadi kecelakaan kerja. Pemakaian alat pelindung diri (APD) merupakan pengendalian risiko yang bersifat sementara. Pemenuhan terhadap alat pelindung diri (APD) bagi tenaga kerja bongkar muat dilaksanakan menurut aturan dan kemampuan dari Koperasi TKBM Usaha Karya. Tenaga kerja bongkar muat lain selain operator crane mendapatkan alat pelindung diri (APD) sesuai situasi dan kondisi kegiatan bongkar muat. Hal ini sesuai dengan ketentuan UndangUndang No. 1 Tahun 1970 Pasal 14 (c) yang menyebutkan bahwa pengurus diwajibkan menyediakan semua alat pelindung diri (APD) pada tenaga kerja yang berada dibawah pimpinannya (Departemen Hukum dan PerundangUndangan, 1970).

Alat pelindung diri (APD) yang diberikan kepada tenaga kerja bongkar muat berupa sepatu safety, helm safety, rompi keselamatan, masker dan sarung tangan. Berdasarkan hasil observasi, tenaga kerja bongkar muat hanya menggunakan sebagian saja dari alat pelindung diri (APD) yaitu berupa rompi keselamatan, helm safety dan sarung tangan. Sepatu safety dan masker hanya digunakanan beberapa tenaga kerja bongkar muat saja. Hasil observasi dan wawancara menyebutkan bahwa banyak tenaga kerja bongkar muat yang tidak nyaman saat menggunakan sepatu safety dan masker. Hal ini menjadi tanggungan petugas safety untuk mengubah ataum melakukan pelatihan yang memberikan pengetahuan pentingnya penggunaan alat pelindung diri (APD) saat bekerja untuk mencegah terjadinya kecelakaan.

\section{KESIMPULAN}

Hasil identifikasi bahaya menunjukkan 17 potensi bahaya yang teridentifikasi. Penilaian risiko menunjukkan 7 potensi bahaya masuk kategori low risk, 6 potensi bahaya masuk kategori medium risk dan 4 potensi bahaya masuk kategori high risk. Pengendalian risiko yang sudah dilakukan terdiri dari pengendalian teknik, pengendalian administratif dan alat pelindung diri (APD).

\section{SARAN}

Koperasi Usaha Karya dan PT Pelabuhan Indonesia III (PERSERO) Cabang Tanjung Perak perlu melakukan pelatihan terkait dengan bongkar muat peti kemas dengan 
Senjayani, et al. Penilaian dan Pengendalian Risiko Pada Pekerjaan Bongkar Muat Peti Kemas Oleh Tenaga Kerja Bongkar Muat Dengan Crane

crane secara periodik. Pemberian reward dan punishment dapat dilakukan oleh PT Pelabuhan Indonesia III (PERSERO) Cabang Tanjung Perak sebagai bentuk memacu ketaatan tenaga kerja bongkar muat sekaligus memacu meningkatkan produktivitas kerja.

\section{DAFTAR PUSTAKA}

Australian Standard/New Zealand Standard. 2004. Australian Standard/New Zealand Standard Risk Management 4360:2004, Sydney and Wellington: Author.

Departemen Hukum dan Perundang-Undangan. 1970. Undang-Undang Nomor 1 Tahun 1970 Tentang Keselamatan Kerja.

Green, L. W. dan K. M. W. 2000. Health Promotion Planning an Education and Environmental Approach. Second Edition, Mayfield Publishing Compa-ny.

Hazyiyah, Ghaisani dan Erwin Dyah Nawawinetu. 2014. Identifikasi Bahaya, Penilaian Risiko Dan Pengendalian Risiko Pada Proses Blasting di PT Cibaliung Sumberdaya, Banten. The Indonesian Journal of Occupational Safe-ty and Health, 3(1), pp. 107-116.

International Labour Organization. 1998. Work Organization and Ergonomics.

Menteri Tenaga Kerja dan Transmigrasi. 1985. Peraturan Menteri Tenaga Kerja dan Transmigrasi Nomor 05 tahun 1985 tentang Pesawat Angkat dan Angkut.

Menteri Tenaga Kerja dan Transmigrasi. 2010. Peraturan Menteri Tenaga Kerja No. 9 Tahun 2010 tentang Operator dan Petugas Pesawat Angkat dan Angkut.

OHSAS 18001:2007. 2007. Occupational Health and Safety Management System Requirement. London: OHSAS Project Group.

Rais, M., P.P. Nugraha, dan W. B. 2009. Kajian Pengaruh Predisposing, Enabling Dan Reinforcing Factors Terhadap Praktek Kerja Tenaga Kerja Bongkar Muat Yang Berisiko Terjadinya Kecelakaan Kerja Di Pelabuhan Tanjung Emas Semarang. The Indonesian Journal of Health Promotion, 4(1). doi: 10.14710/jpki.4.1.36-49.

Ramli, S. 2010. Sistem Manajemen Keselamatan dan Kesehatan Kerja (OHSAS 18001). Jakarta: PT Dian Rakyat.

Retno Wulan Dari dan Indriati Paskarin. 2013. Risk Management Pada Pekerja Gondola Pa-ket III Proyek Pengembangan Bandara
JPH RECODE Maret 2018; 1 (2) : 120-130 http://e-journal.unair.ac.id/JPHRECODE

In-ternasional Ngurah Rai-Bali (PPBIB), KSO Adhi-Wika. The Indonesian Journal of Occupational Safe-ty and Health, 2(1), pp. 20-27.

Riski, R. 2013. Hubungan Antara Masa Kerja dan Pemakaian Masker Sekali Pakai dengan Kapasitas Vital Paru pada Pekerja Bagian Composting di PT. Zeta Agro Corporation Brebes. Skripsi, Universitas Negeri Semarang.

Septiana, D. A. dan Mulyono. 2014. Faktor Yang Mempengaruhi Unsafe Action Pada Pekerja di Bagian Pengantongan Urea. The Indonesian Jiurnal of Occupational Safety and Health, 3(1), pp. 25-34.

Siswanto, A. 2012. Materi Perkuliahan Job Safety Analysis. Surabaya: Fakultas Kesehatan Masyarakat Universitas Airlangga.

Suardi, R. 2007. Sistem Manajemen Keselamatan dan Kesehatan Kerja. Jakarta : PPM.

Suma'mur, P. K. 2009. Higiene perusahaan dan kesehatan kerja (Hiperkes). Jakarta: Sagung Seto.

Tarwaka. 2008. Keselamatan dan Kesehatan Kerja: Manajemen dan implementasi $\mathrm{K} 3$ di Tempat Kerja. Surakarta: Harapan Press.

Tyastanti, C.L., dan A. Y. D. 2014. Risk Assessment Kecelakaan Kerja Pada Unit Windin PT. Kusumaputra Santosa, Karangan-yar, Jawa Tengah. The Indonesian Journal of Occupa-tional Safety and Health, 3(2), pp. 128-137.

Wicaksono, R. Y. 2017. Risk Management Keselamatan Dan Kesehatan Kerja Pada Engine Room Kapal Feri Selat Madura Ii Surabaya. Journal of Public Health Research and Community Health Development, 1(1), pp. 50-62.

Yosia Parlindungan Bangun dan Erwin Dyah Nawawinetu. 2014. Risk Assessment Pada Pekerja Mainte-nance di PT X. The Indonesian Journal of Occupational Safety and Health, 3(2), pp. 170-181. 